\title{
Integrated Surface/Subsurface Flow Modeling in PFLOTRAN
}

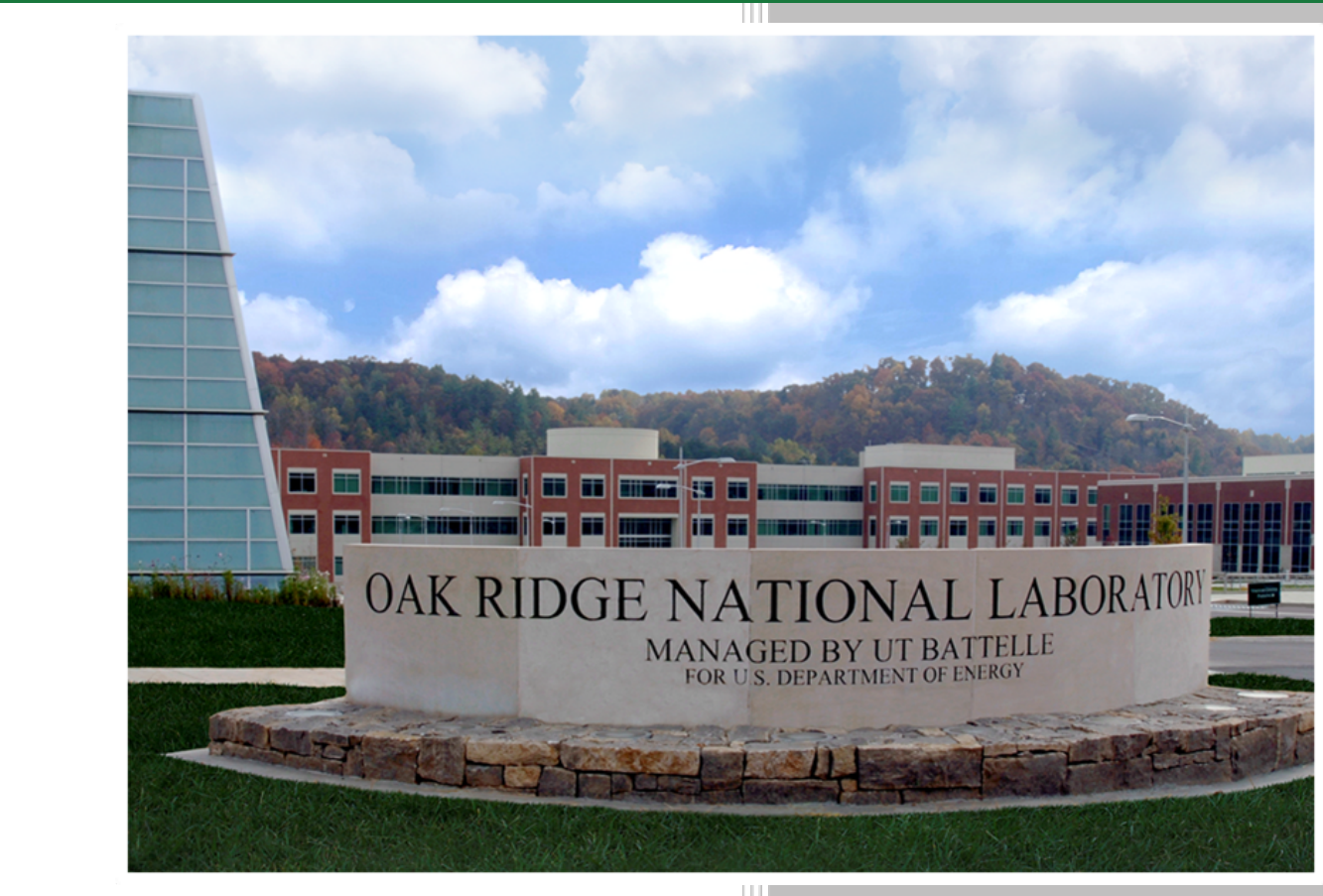

Approved for public release. Distribution is unlimited.
S. L. Painter

N. Collier

A. Jan

October 2016 


\section{DOCUMENT AVAILABILITY}

Reports produced after January 1, 1996, are generally available free via US Department of Energy (DOE) SciTech Connect.

Website http://www.osti.gov/scitech/

Reports produced before January 1, 1996, may be purchased by members of the public from the following source:

National Technical Information Service

5285 Port Royal Road

Springfield, VA 22161

Telephone 703-605-6000 (1-800-553-6847)

TDD 703-487-4639

Fax 703-605-6900

E-mail info@ntis.gov

Website http://www.ntis.gov/help/ordermethods.aspx

Reports are available to DOE employees, DOE contractors, Energy Technology Data Exchange representatives, and International Nuclear Information System representatives from the following source:

Office of Scientific and Technical Information

PO Box 62

Oak Ridge, TN 37831

Telephone 865-576-8401

Fax 865-576-5728

E-mail reports@osti.gov

Website http://www.osti.gov/contact.html

This report was prepared as an account of work sponsored by an agency of the United States Government. Neither the United States Government nor any agency thereof, nor any of their employees, makes any warranty, express or implied, or assumes any legal liability or responsibility for the accuracy, completeness, or usefulness of any information, apparatus, product, or process disclosed, or represents that its use would not infringe privately owned rights. Reference herein to any specific commercial product, process, or service by trade name, trademark, manufacturer, or otherwise, does not necessarily constitute or imply its endorsement, recommendation, or favoring by the United States Government or any agency thereof. The views and opinions of authors expressed herein do not necessarily state or reflect those of the United States Government or any agency thereof. 
Environmental Sciences Division

\title{
Integrated Surface/Subsurface Flow Modeling in PFLOTRAN
}

\author{
Scott L Painter \\ Nathan Collier \\ Ahmad Jan
}

Date Published:

October 6, 2016

\author{
Prepared by \\ OAK RIDGE NATIONAL LABORATORY \\ Oak Ridge, TN 37831-6283 \\ managed by \\ UT-BATTELLE, LLC \\ for the \\ US DEPARTMENT OF ENERGY \\ under contract DE-AC05-00OR22
}





\section{CONTENTS}

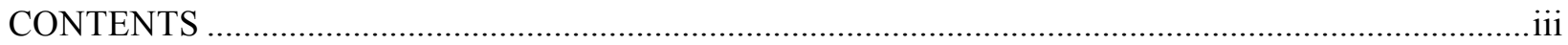

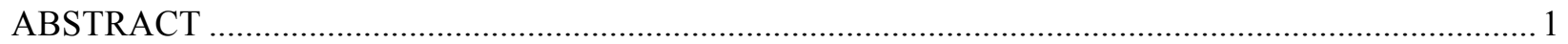



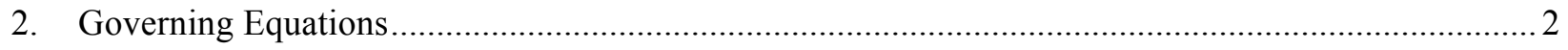



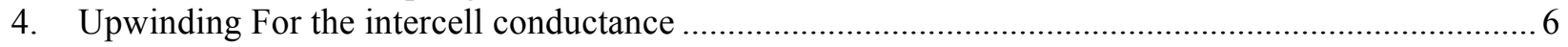

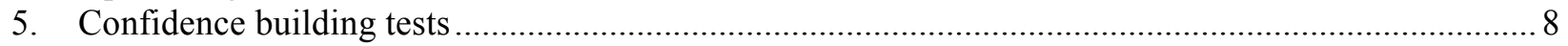

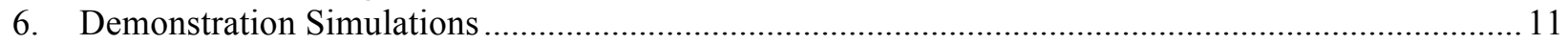

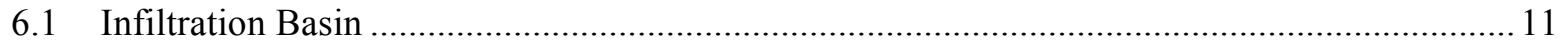

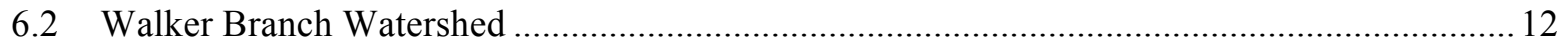



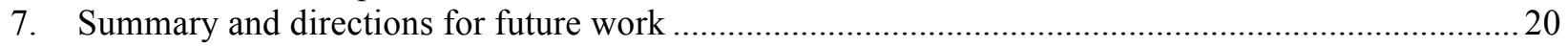

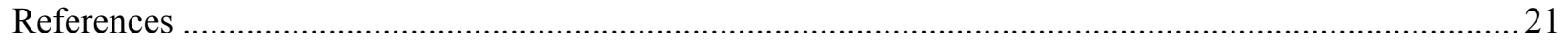




\section{ACKNOWLEDGMENTS}

Research sponsored by the Laboratory Directed Research and Development Program of Oak Ridge National Laboratory, managed by UT-Battelle, LLC, for the U. S. Department of Energy. The authors are also grateful to Fengming Yuan for careful review of the manuscript. 


\begin{abstract}
Understanding soil water, groundwater, and shallow surface water dynamics as an integrated hydrological system is critical for understanding the Earth's critical zone, the thin outer layer at our planet's surface where vegetation, soil, rock, and gases interact to regulate the environment. Computational tools that take this view of soil moisture and shallow surface flows as a single integrated system are typically referred to as integrated surface/subsurface hydrology models. We extend the open-source, highly parallel, subsurface flow and reactive transport simulator PFLOTRAN to accommodate surface flows. In contrast to most previous implementations, we do not represent a distinct surface system. Instead, the vertical gradient in hydraulic head at the land surface is neglected, which allows the surface flow system to be eliminated and incorporated directly into the subsurface system. This tight coupling approach leads to a robust capability and also greatly simplifies implementation in existing subsurface simulators such as PFLOTRAN. Successful comparisons to independent numerical solutions build confidence in the approximation and implementation. Example simulations of the Walker Branch and East Fork Poplar Creek watersheds near Oak Ridge, Tennessee demonstrate the robustness of the approach in geometrically complex applications. The lack of a robust integrated surface/subsurface hydrology capability had been a barrier to PFLOTRAN's use in critical zone studies. This work addresses that capability gap, thus enabling PFLOTRAN as a community platform for building integrated models of the critical zone.
\end{abstract}

\title{
1. INTRODUCTION
}

Integrated hydrology modeling, which views shallow surface and subsurface flows as an integrated system, is a key enabling capability for understanding and projecting environmental processes at and near the land surface. Such integrated surface/subsurface hydrology models are needed in a variety of application areas ranging from watershed management and water supply protection to supporting studies of critical zone processes.

Several integrated surface/subsurface simulation tools have emerged in recent years (see Maxwell et al. (2014) for a review) and employ a variety of strategies to address the numerical challenges of integrated hydrology, which include distinct time scales for the surface and subsurface responses and need to represent transitions between wet and dry conditions on the surface. Here we present an alternative scheme for coupling surface and subsurface flows in integrated hydrological models and an implementation in the open-source subsurface simulator PFLOTRAN (Hammond et al. 2014, Lichtner et al. 2016). In contrast to most formulations, we do not represent a distinct surface system. Instead, we neglect the vertical gradient in hydraulic head at the land surface, which allows the surface flow system to be eliminated and incorporated directly into the subsurface system. This tight coupling approach leads to a robust capability and also greatly simplifies implementation in existing subsurface simulators such as PFLOTRAN.

PFLOTRAN is an open-source, highly parallel subsurface flow and reactive transport simulator. Its strengths include rich and flexible geochemical reaction capabilities, good parallel scaling on mid-range and leadership-class high-performance computing resources, and ability to use fully unstructured computational meshes. Those capabilities make PFLOTRAN an attractive platform for next-generation process-rich watershed and ecohydrological models. The lack of a robust integrated surface/subsurface hydrology capability has been a barrier to that application, however. One of the objectives of this work is to address that capability gap, thus enabling PFLOTRAN to be used as a community watershed/ecohydrological tool. 


\section{GOVERNING EQUATIONS}

For overland flow, we use the following form of the diffusion wave equation

$$
\begin{gathered}
\frac{\partial\left[\eta_{l} h\right]}{\partial t}+\nabla \cdot\left(\eta_{l} h \mathbf{U}_{s}\right)=q_{w}-\Gamma_{e x} \\
\mathbf{U}_{s}=-\frac{h^{2 / 3}}{n_{\text {man }} S^{1 / 2}} \nabla(Z+h)
\end{gathered}
$$

Here $t$ is time, the dependent variable is the liquid ponded depth $h(x, y)$ where $x$ and $y$ are horizontal coordinates, and the gradient and divergence operators are to be interpreted in $2 \mathrm{D}$. In addition, $Z$ is the surface elevation, $\eta_{l}$ is liquid molar density, $S=\|\nabla Z\|$ is the bed slope, $n_{\text {man }}$ is Manning's parameter, $q_{w}$ is the explicit source of water (precipitation net of evaporation, in moles $/ \mathrm{m}^{2}-\mathrm{s}$ ), $\Gamma_{e x}$ is exchange between the surface and subsurface (moles $\left./ \mathrm{m}^{2}-\mathrm{s}\right)$, and $\mathbf{U}_{s}$ is surface flow velocity $(\mathrm{m} / \mathrm{s})$. We use bed slope in the denominator rather than the slope of the ponded water elevation $\|\nabla(Z+h)\|$ to reduce the degree of nonlinearity in the equation. This formulation is intermediate between the kinematic wave equation and diffusion wave equation. Experience has shown (Painter et al. 2016) that use of bed slope instead of water-elevation slope significantly improves convergence while giving nearly identical results. It is important to note that we use conservation of moles instead of the usual volumetric conservation equation to be consistent with PFLOTRAN's subsurface capability.

For the subsurface, we use the 3D mass conserving "mixed form" of Richards equation with liquid pressure as the primary variable

$$
\begin{gathered}
\frac{\partial}{\partial t}\left[\phi \eta_{l} s_{l}\right]=-\nabla \cdot\left[\eta_{l} \mathbf{U}\right]-Q_{\text {tran }} \\
\mathbf{U}=-\frac{k_{r l} k}{\mu_{l}} \nabla\left[p_{l}+\rho_{l} g z\right]
\end{gathered}
$$

Here $s_{l}$ is the liquid saturation index, $p_{l}$ is liquid pressure, $\phi$ is porosity, $\mathbf{U}$ is the Darcy velocity, $k$ is absolute permeability, $k_{r}$ is relative permeability, $u_{l}$ is dynamic viscosity of liquid water, $\rho_{l}$ is liquid mass density, $g$ is acceleration due to gravity, and $z$ is the vertical coordinate (positive upward), and $Q_{\text {tran }}$ is root water uptake from transpiration. It is important to note that Eq. (3) is valid in saturated or unsaturated conditions. Instead of incorporating a soil specific storage term, we take the equivalent approach of making porosity and the liquid density a function of the liquid pressure to model soil and water compressibility effects.

To fully specify the system, we also relate liquid saturation to liquid pressure as $S_{l}=S_{*}\left(p_{l}-p_{a t m}\right)$, where $p_{a t m}$ is atmospheric pressure and $S_{*}$ is the soil moisture characteristic curve. The empirical 
relationship developed by Van Genuchten (1980) is used for $S_{*}$ here, although PFLOTRAN has several options. That van Genuchten relationship is combined with Mualem's (1976) relationship to specify the relative permeability.

Finally, the boundary condition at the surface is

$$
\left.\eta_{l} \mathbf{U} \cdot \hat{\mathbf{z}}\right|_{t o p}=\Gamma_{e x}
$$

The exchange flux links the surface and subsurface systems. It appears an areal source in the 2-D surface system Eq. (1) and in the top boundary condition for the 3-D subsurface.

\section{DISCRETIZATION AND COUPLING}

Our approach is to discretize the surface and subsurface water conservation equations using the finite volume method, and then incorporate the discretized surface system into the uppermost cells of the subsurface by assuming the surface ponded depth is in dynamic equilibrium with the top of the subsurface.

We require the subsurface domain be discretized into vertically oriented prisms with general polygons on the top and bottom ends. The uppermost layer of cells is uniform thickness $\Delta Z_{\text {top }}$. Geometrical quantities are defined in cross-section for the $i$-th cell in Figure 1 . The i-th cell has a set of $N_{i}$ neighbors and a set $N_{H, i}$ of horizontal neighbors. The $i$-th cell also has volume $V_{i}$. Two neighboring cells $i$ and $j$ share a face

with area $A_{i j}$. The surface polygons of those two cells share an edge with length $L_{i j=} \frac{A_{i j}}{\Delta Z_{t o p}}$. The distance between the two cell centers is $d_{i j}$. 


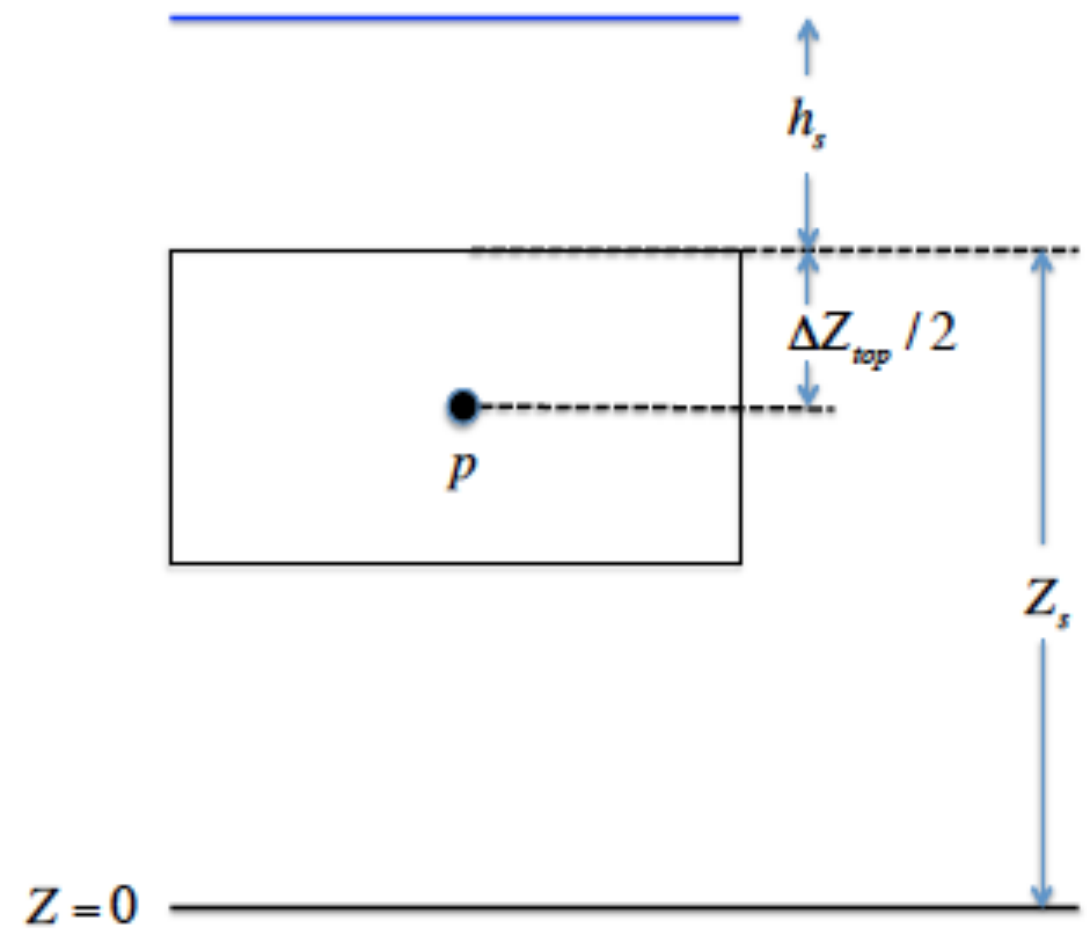

Figure 1. Geometrical quantities at the top cell.

The discretized form of the Richards equation over a control volume $i$ inside the uppermost layer of the subsurface domain is

$$
\left[\frac{\left(\eta_{l} \phi s\right)_{i}^{t+\Delta t}-\left(\eta_{l} \phi s\right)_{i}^{t}}{\Delta t}\right] V_{i}+\sum_{j=1}^{N_{\text {faces }}} U_{i j}^{t+\Delta t} A_{i j}=-Q_{\text {tran }}^{t+\Delta t} V_{i}+q_{e x} A_{i, t o p}
$$

where $t$ is time, $d t$ is the time step size, $V$ is cell volume, $U_{i j}$ is the mass flux between cell $i$ and its neighboring cell $j, q_{e x}$ is the mass flux between the surface and subsurface.

The discretized form of the surface water conservation equation is given by

$$
\left[\frac{\left(\eta_{l} h\right)_{i}^{t+\Delta t}-\left(\eta_{l} h\right)_{i}^{t}}{\Delta t}\right] A_{i, \text { top }}+\sum_{j=1}^{N_{\text {faces }}}\left(\eta_{l} h U_{s}\right)_{i j}^{t+\Delta t} L_{i j}=q_{\text {precip }}^{t+\Delta t} A_{i, \text { top }}-q_{e x} A_{i, t o p}
$$


We assume no vertical gradient in pressure at the surface (dynamic equilibrium between surface and subsurface). With this approximation, the ponded water depth is related to the pressure in the uppermost cell as

$$
h=\max \left[\frac{p-p_{a t m}}{\rho_{l} g}-\frac{\Delta Z_{t o p}}{2}, 0\right]
$$

Numerical tests suggest that it is advantageous to neglect the $\Delta Z_{\text {top }}$ term and approximate $h$ as

$$
h=\max \left[\frac{p-p_{a t m}}{\rho_{l} g}, 0\right]
$$

This is conceptually equivalent to relocating the node to the face of the subsurface cell, which introduces additional discretization error in the subsurface since the unknown pressure is not calculated at the cell centroid. However, this error can be controlled by keeping the size of the uppermost cell small. Thus, unless otherwise noted we use Eq. (9).

Combining Eqs. (6) and (7), the subsurface mass residual equation for the top layer becomes,

$$
\begin{aligned}
& {\left[\frac{\left(\eta_{l} \phi s\right)_{i}^{t+\Delta t}-\left(\eta_{l} \phi s\right)_{i}^{t}}{\Delta t}\right] V_{i}+\sum_{j=1}^{N_{\text {faces }}} q_{i j}^{t+\Delta t} A_{i j}+} \\
& {\left[\frac{\left(\eta_{l} h\right)_{i}^{t+\Delta t}-\left(\eta_{l} h\right)_{i}^{t}}{\Delta t}\right]_{i, \text { top }}+\sum_{j=1}^{N_{\text {vaces }}}\left(\eta_{l} h U_{s}\right)_{i j}^{t+\Delta t} L_{i j}=} \\
& Q_{w}^{t+\Delta t} V_{i}+q_{\text {precip }}^{t+\Delta t} A_{i, \text { top }}
\end{aligned}
$$

Eq. (10) with Eq. (9) is the key to the integrated surface/subsurface capability described here. Basically, we tag the top layer of cells in the subsurface for special treatment when forming the mass balance residual in PFLOTRAN. When the liquid pressure is less than atmosphere pressure, which indicates the cell is unsaturated, the second and third terms on the left are 0 , precipitation flux is applied directly to the subsurface, and PFLOTRAN proceeds to solve Richards equation as usual. When a topmost cell fills with water, which corresponds to the liquid pressure reaching atmospheric, the additional residual terms for surface water accumulation (third term on left) and surface flow (fourth term on left) are triggered. Thus, the surface flow is implicit in the formulation of the modified subsurface residual equations and does not require any additional solver or mesh infrastructure. We refer to this as "in-line" surface flow.

PFLOTRAN uses implicit time stepping (backward Euler method) and at each time step, Newton iteration is required to resolve nonlinearities. Thus, we also need expressions for the Jacobian matrix (derivatives of the residual equations with respect to the primary variables - pressures in this case). The new terms in the Jacobian matrix are given in Appendix A. 


\section{UPWINDING FOR THE INTERCELL CONDUCTANCE}

Recall that in the finite volume method, the unknowns reside at cell centers. Thus, some averaging scheme is needed to relate quantities at the interface (denoted with the $i j$ subscript above) to cell-based quantities. PFLOTRAN uses the two-point flux approximation to calculate flux at the cell faces based on cell pressures. Focusing on the surface terms (fourth term in Eq. 10) and dropping the $t+\Delta t$ superscript for clarity, the molar flux between cells $i$ and $j$ may be approximated as

$$
\left(\eta_{l} h U_{s}\right)_{i j}=\frac{\eta_{l, i j} h_{i j}^{5 / 3}}{n_{\text {man, }, i j} d_{i j}} \frac{(Z+h)_{i}-(Z+h)_{j}}{\sqrt{S}}
$$

We now need to define the terms in the intercell conductance. For the subsurface, PFLOTRAN adopts the well-established scheme of harmonic averaging for the absolute permeability with relative permeability based on the upstream cell. Harmonic averaging of the absolute permeability gives the correct flux for a given pressure drop when the flow is perpendicular to a layered system. Upwinding - using relative permeability in cell $i$ when flow is from cell $i$ to cell $\mathrm{j}$, and conversely when flow is in the opposite direction - is preferred for the relative permeability on physical grounds because that scheme will not allow flow to leave a dry cell but will allow cell to enter a dry cell.

Clearly some form of upwinding is needed for the surface flux as well. Specifically, we need to base the average $h_{i j}$ on $h_{i}$ if flow is from cell $i$ to $j$ and on $h_{j}$ if flow is in the opposite direction. However, intercell averaging for the surface system is different from the subsurface because the flow direction is based on $Z+h$ which is different from the quantity to be upwinded $h$. We now discuss how a simple upwinding scheme is not ideal in this case and propose an alternative upwinding formula.

Based on previous work in a related context (Painter et al. 2008) we propose the following new scheme:

$$
\begin{aligned}
& \text { If }(Z+h)_{i}>(Z+h)_{j} \text { then } h_{i j}=h_{i}+Z_{i}-\max \left(Z_{i}, Z_{j}\right) \\
& \text { If }(Z+h)_{j}>(Z+h)_{i} \text { then } h_{s, i j}=h_{j}+Z_{j}-\max \left(Z_{i}, Z_{j}\right)
\end{aligned}
$$

The motivation for this scheme can be understood by referring to Figure 2. In this figure, the water elevation (denoted by the sloping blue line) is slightly higher in cell $i$ compared with cell $j$, but the land surface elevation is higher in cell $j$. If we were to use a naïve upwinding scheme, then the full ponded depth $h_{i}$ would be used to determine the intercell conductance. In our scheme, we reduce this by the amount $Z_{j}-Z_{i}$, so that the smaller ponded depth is used to calculate the intercell conductance. In addition to being intuitively appealing to not use the full value $h_{i}$ in this example (see Figure 2), the upwinding scheme Eqs (12) and (13) results in continuous derivatives of the residual term $\left(\eta_{l} h U_{s}\right)_{i j}$ with respect to both $h_{i}$ and $h_{j}$ as the gradient in water elevation $Z+h$ passes through zero (i.e. when flow direction changes). To show this we take, without loss of generality, $Z_{i}>Z_{j}$, and look at derivatives of $\left(\eta_{l} h U_{s}\right)_{i j}$ with respect to $h_{i}$ as $(Z+h)_{i}-(Z+h)_{j}$ approaches 0 from either direction.

When $(Z+h)_{i} \geq(Z+h)_{j}$ our upwinding scheme gives $h_{i j}=h_{i}$ and

$$
A \frac{\partial\left(\eta_{l} h U_{s}\right)_{i j}}{\partial h_{i}}=\frac{5}{3} h_{i}^{2 / 3}\left[(Z+h)_{i}-(Z+h)_{j}\right]+h_{i}^{5 / 3}
$$


where A is a constant (independent of $h_{i}$ and $h_{j}$ ). Letting $h_{i}$ approach $h_{j}+Z_{j}-Z_{i}$ from the above and using the subscript + to indicate we are evaluating there

$$
\left.A \frac{\partial\left(\eta_{l} h U_{s}\right)_{i j}}{\partial h_{i}}\right|_{+}=h_{i}^{5 / 3}
$$

When $(Z+h)_{j}>(Z+h)_{i}$ our upwinding scheme gives $h_{i j}=h_{j}+Z_{j}-Z_{i}$ and

$$
A \frac{\partial\left(\eta_{l} h U_{s}\right)_{i j}}{\partial h_{i}}=\left(h_{j}+Z_{j}-Z_{i}\right)^{5 / 3}
$$

At the point of flow change - that is, as $h_{i}$ approaches $h_{j}+Z_{j}-Z_{i}$ from below - the term in parentheses is $h_{i}$. Thus

$$
\left.A \frac{\partial\left(\eta_{l} h U_{s}\right)_{i j}}{\partial h_{i}}\right|_{-}=h_{i}^{5 / 3}
$$

Thus, derivatives of the mass residual equations are continuous as flow changes direction. A simple upwinding scheme, by contrast, would have a discontinuity in the derivative, which can cause convergence failures in a Newton scheme. Indeed, when implemented in PFLOTRAN our upwinding scheme resulted in many fewer time step failures and larger time steps compared with a simple upwinding scheme. Similar behavior has been reported in a similar system (Painter et al. 2008).

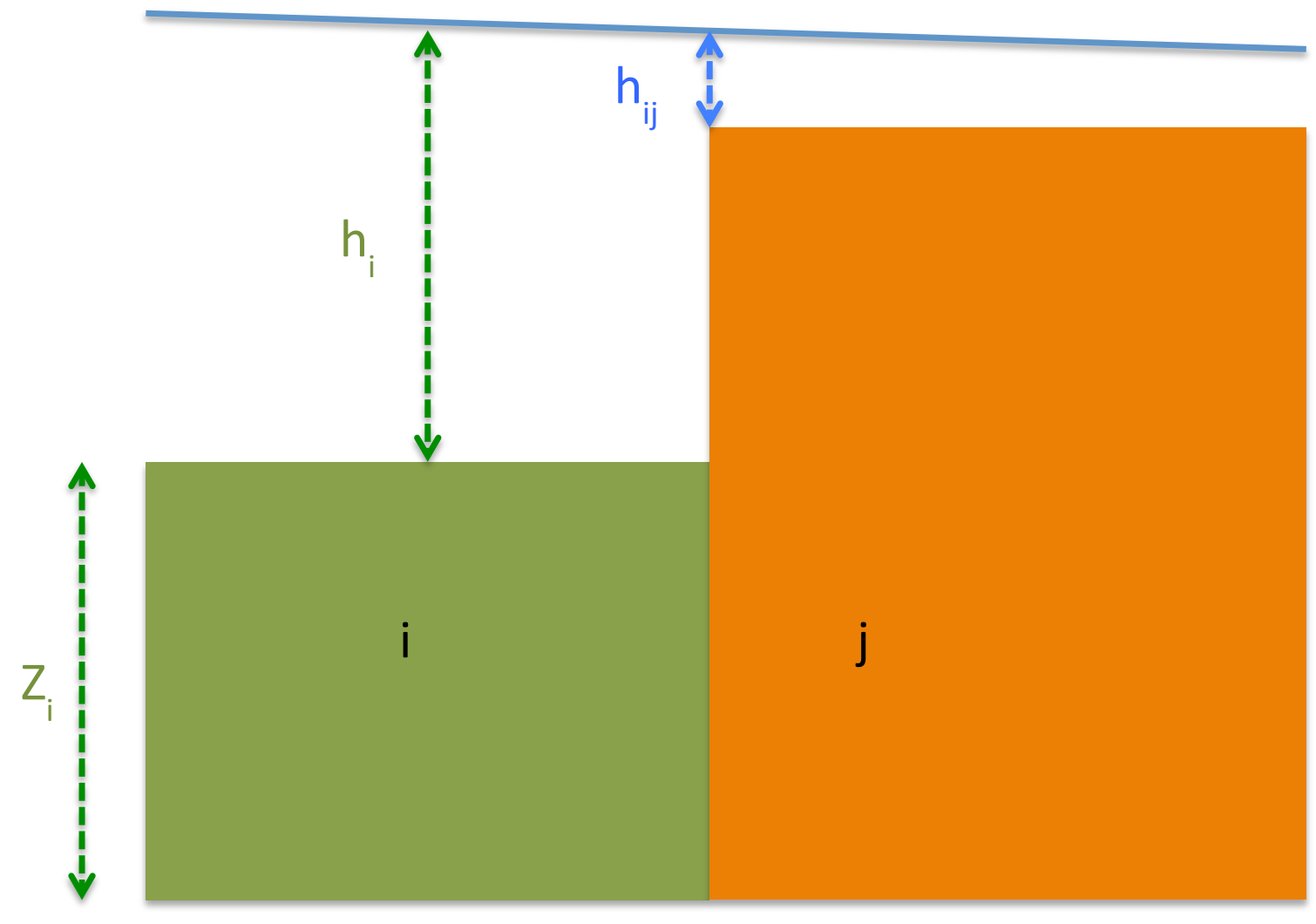

Figure 2. New upwinding scheme used here. See text for details. 


\section{CONFIDENCE BUILDING TESTS}

We used three sets of simulations on a sloping plane configuration to build confidence in the approach and implementation. The geometry, which was used by others in tests of integrated surface/subsurface flow (Maxwell et al. 2014, Sulis et al. 2010, Kollet and Maxwell 2006), is a $320 \mathrm{~m}$ by $400 \mathrm{~m}$ plane with slope of 0.0002 . The soil has a uniform depth of $5 \mathrm{~m}$. Vertical spacing is uniform at $5 \mathrm{~cm}$. Horizontal spacing ranges from $20 \mathrm{~m}$ to $80 \mathrm{~m}$, depending on the case, and is the same for the two horizontal directions. The three cases differ in the value of soil hydraulic conductivity relative to infiltration. A surface only system is obtained by setting soil permeability and porosity to very small values. An infiltration excess case is obtained when the soil hydraulic conductivity is non-zero, but smaller than the precipitation rate. In this case, the uppermost layer of cells fills with water and triggers surface runoff. In the saturation excess case, the hydraulic conductivity is larger than the precipitation rate. In this case precipitation infiltrates and raises the water table until it expresses on the surface. In all cases, a zero gradient in ponded depth was the downstream boundary condition on the surface. No-flow conditions were used on the other sides of the top surface and for the subsurface. We simulated two variants for each of those three cases. We also implemented the heterogeneous slab configuration of Sulis et al. (2010). That case is a hybrid between the infiltration excess and saturation excess cases. It has parameters of the saturation excess case except for a low-permeability region centered at the land surface with horizontal extent of $100 \mathrm{~m}$. Parameters for the three cases are shown in Table 1.

In all cases, we monitored outflow versus time (hydrograph) and compared with independent numerical solutions. For the surface-only simulation, an independent numerical solution was developed using the partial differential solver NDSolve in Mathematica ${ }^{\mathrm{TM}}$ (Wolfram Research 2014). Hydrographs for the saturation excess and infiltration excess cases were digitized from Kollet and Maxwell (2006) or Sulis et al. (2010), who simulated the same setup.

Table 1. Parameters for the confidence building tests.

\begin{tabular}{|c|c|c|c|c|c|c|c|}
\hline & \multicolumn{2}{|c|}{ Surface only } & \multicolumn{2}{|c|}{ Saturation excess } & \multicolumn{2}{|c|}{ Infiltration excess } & \multirow{2}{*}{$\begin{array}{c}\text { Heterogeneous } \\
\text { slab } \\
10\end{array}$} \\
\hline Horizontal spacing $(\mathrm{m})$ & 20 & 20 & 80 & 80 & 80 & 80 & \\
\hline Manning's $n\left(\mathrm{~s}-\mathrm{m}^{-1 / 3}\right)$ & 0.2 & 0.02 & 0.02 & 0.02 & 0.02 & 0.02 & 0.02 \\
\hline Precipitation rate $(\mathrm{mm} / \mathrm{min})$ & 0.33 & 0.33 & 0.33 & 0.33 & 0.33 & 0.33 & 0.33 \\
\hline Initial water table depth (m) & $\mathrm{N} / \mathrm{A}$ & $\mathrm{N} / \mathrm{A}$ & 1 & 0.5 & 1 & 1 & 1 \\
\hline Soil permeability $\left(\mathrm{m}^{2}\right)$ & 0 & 0 & $\begin{array}{l}1.18 \times \\
10^{-12}\end{array}$ & $\begin{array}{l}1.18 \times \\
10^{-12}\end{array}$ & $\begin{array}{l}1.18 \times \\
10^{-13}\end{array}$ & $\begin{array}{l}1.18 \times \\
10^{-14}\end{array}$ & variable \\
\hline Soil porosity & 0 & 0 & 0.4 & 0.4 & 0.4 & 0.4 & 0.4 \\
\hline van Genuchten's $\alpha\left(\mathrm{m}^{-1}\right)$ & $\mathrm{N} / \mathrm{A}$ & $\mathrm{N} / \mathrm{A}$ & 1 & 1 & 1 & 1 & 1 \\
\hline van Genuchten's $n(-)$ & $\mathrm{N} / \mathrm{A}$ & $\mathrm{N} / \mathrm{A}$ & 2 & 2 & 2 & 2 & 2 \\
\hline Residual saturation (-) & N/A & N/A & 0.2 & 0.2 & 0.2 & 0.2 & 0.2 \\
\hline
\end{tabular}

Outflows in $\mathrm{m}^{3} /$ day for the two surface-only cases are compared with an independent numerical solution in Figure 3. There are some minor differences around 75 minutes in the case with smaller Manning's $n$, but in general, the agreement is quite good.

Calculated volumetric outflows per unit length $\left[\mathrm{m}^{2} / \mathrm{s}\right]$ for the two saturation-excess cases are compared to results from Kollet and Maxwell (2006) in Figure 4. The agreement is good across the entire range. 
Calculated volumetric outflows per unit length $\left[\mathrm{m}^{2} / \mathrm{s}\right]$ for the two infiltration-excess cases are compared to results from Kollet and Maxwell (2006) in Figure 5. In these two cases the agreement is good on the rising limb of the hydrograph and on recession portion in the lower permeability case. The PFLOTRAN result is slightly higher than Kollet and Maxwell on the recession portion of the hydrograph in the lower permeability case. The small difference is likely due to differences in the coupling schemes, the way soil specific storage is implemented, or in the downstream boundary condition.

Calculated volumetric outflow for the heterogeneous slab case is compared with results from Sulis et al. (2010) in Figure 7. The two codes agree well in terms of the initial rise, peak, and recession curve. There are differences around $125-150$ minutes, where the Sulis et al. (2010) result has a pronounced plateau, which is more rounded in the PFLOTRAN case. Nevertheless, the agreement is reasonable given that Sulis et al. (2010) implemented a kinematic wave model for overland flow and PFLOTRAN uses the diffusion wave model.



Figure 3. Outflows in $\mathrm{m} 3$ /day for the two surface-only cases. Red curves are solutions to the diffusion-wave equation obtained with MathematicaTM. Blue dots are from PFLOTRAN. The upper two curves are for the case with smaller Manning's n (see Table 1). 




Figure 4. Calculated volumetric outflows per unit length $\left[\mathrm{m}^{2} / \mathrm{s}\right]$ for the two saturation excess cases. Red curves are from Figure 7 of Kollet and Maxwell, blue curve are from PFLOTRAN. The upper two curves are for the case with higher initial water table (see Table 1).

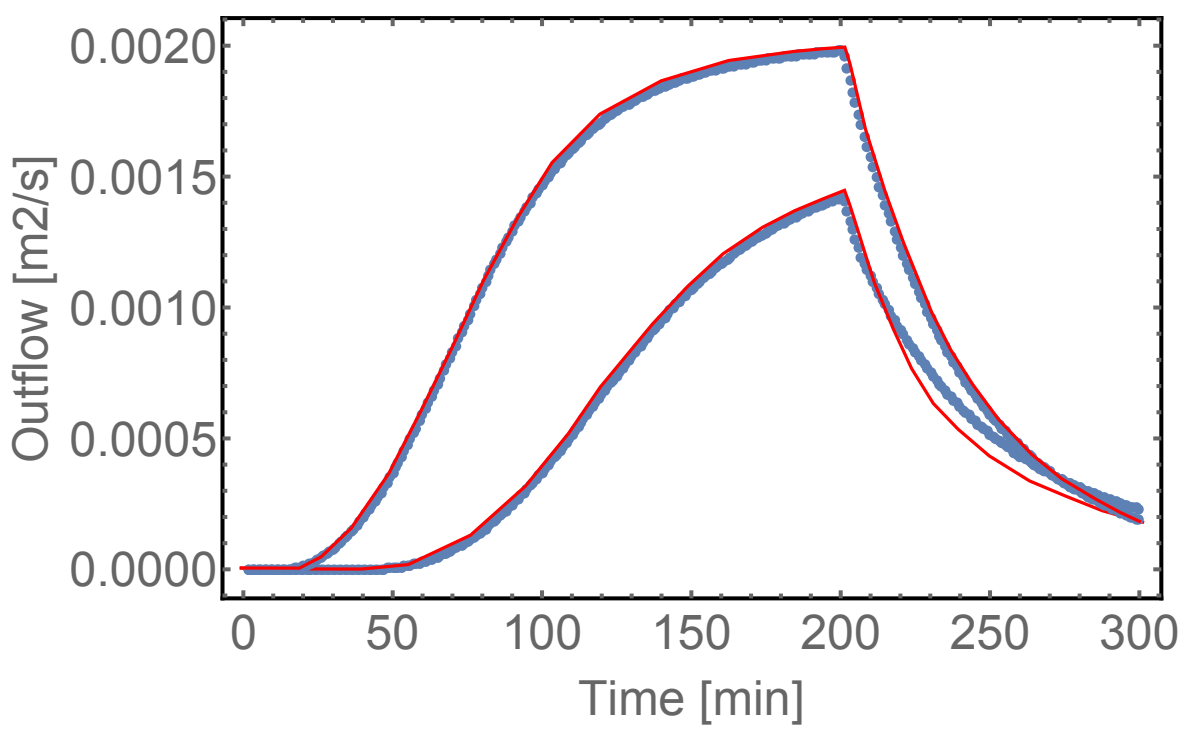

Figure 5. Calculated volumetric outflows per unit length $\left[\mathrm{m}^{2} / \mathrm{s}\right]$ for the two infiltration-excess cases. Red curves are from Figure 8 of Kollet and Maxwell [2006]. Blue dots are from PFLOTRAN. The upper two curves are for the case with lower saturated hydraulic conductivity (see Table 1). 




Figure 6. Calculated volumetric outflows $[\mathrm{m} 2 / \mathrm{s}]$ for the heterogeneous slab test case. Red curves are Parflow results from Figure 5 of Sulis et al. [2010]. Blue dots are from PFLOTRAN.

\section{DEMONSTRATION SIMULATIONS}

Three sets of simulations were used to verify that the new coupling scheme and implementation in PFLOTRAN performs well under conditions of interest for applications.

\subsection{INFILTRATION BASIN}

The first test involves an infiltration basin, an engineered feature that is used in stormwater management to temporarily store surface runoff allowing it time to infiltrate into the soil. Results of an integrated surface/subsurface simulation are shown in cross-section in Figure 7 for a hypothetical infiltration basin. The color map is saturation index for soil moisture. The level of ponded water is shown as a teal line above the topography. The near-surface soil in this simulation has properties of a relatively lowpermeability clay, which forces overland flow to form and runoff into the basin. Over time, the water ponds to sufficient depth to force infiltration into the subsurface. The surface ponded depth was initially

zero in this simulation, so the simulation tests the robustness of our implementation in transitioning from dry to wet conditions, as well as overland flow, accumulation of water in depressions, and slow infiltration from a ponded state. 

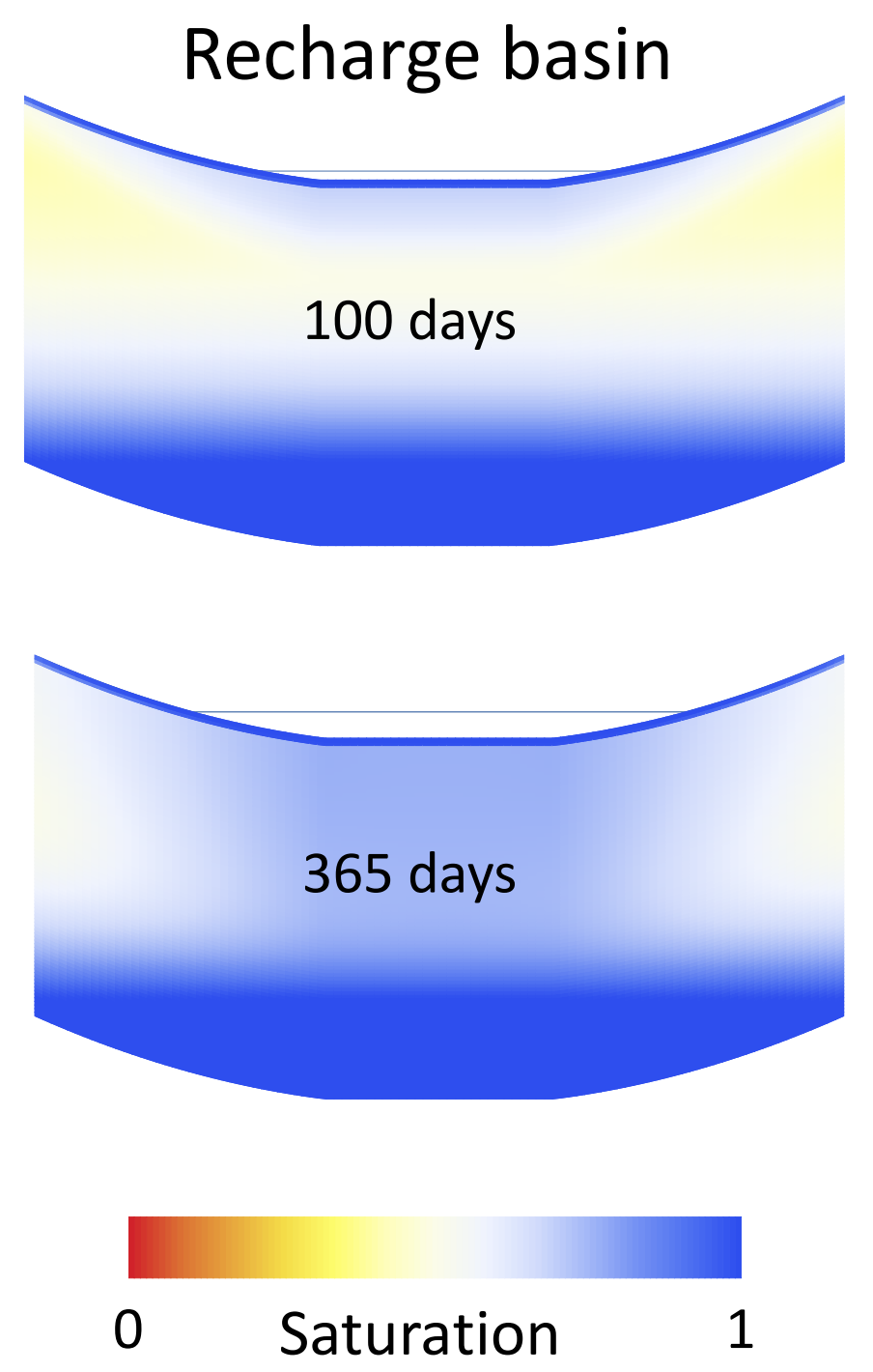

Figure 7. Results from infiltration basin simulation

\subsection{WALKER BRANCH WATERSHED}

The second demonstration simulation used topography of the Walker Branch Watershed near Oak Ridge, Tennessee. An unstructured mesh following the topography was constructed at resolution of approximately $7 \mathrm{~m}$. Each of the triangular surface elements was extruded into subsurface forming a prismatic finite volume mesh for PFLOTRAN. The soil depth was assumed to be uniform at $15 \mathrm{~m}$. Vertical resolution is $0.05 \mathrm{~cm}$ at the surface and becames coarser with depth.

This test was intended to be a "stress test" of robustness, not a realistic simulation. For that reason, we started the system in a fairly dry state and used a 5 hour precipitation event of $1.8 \mathrm{~m}$. We ran these simulations in parallel on 16 cores. Results for the surface system are shown in Figure 8. 

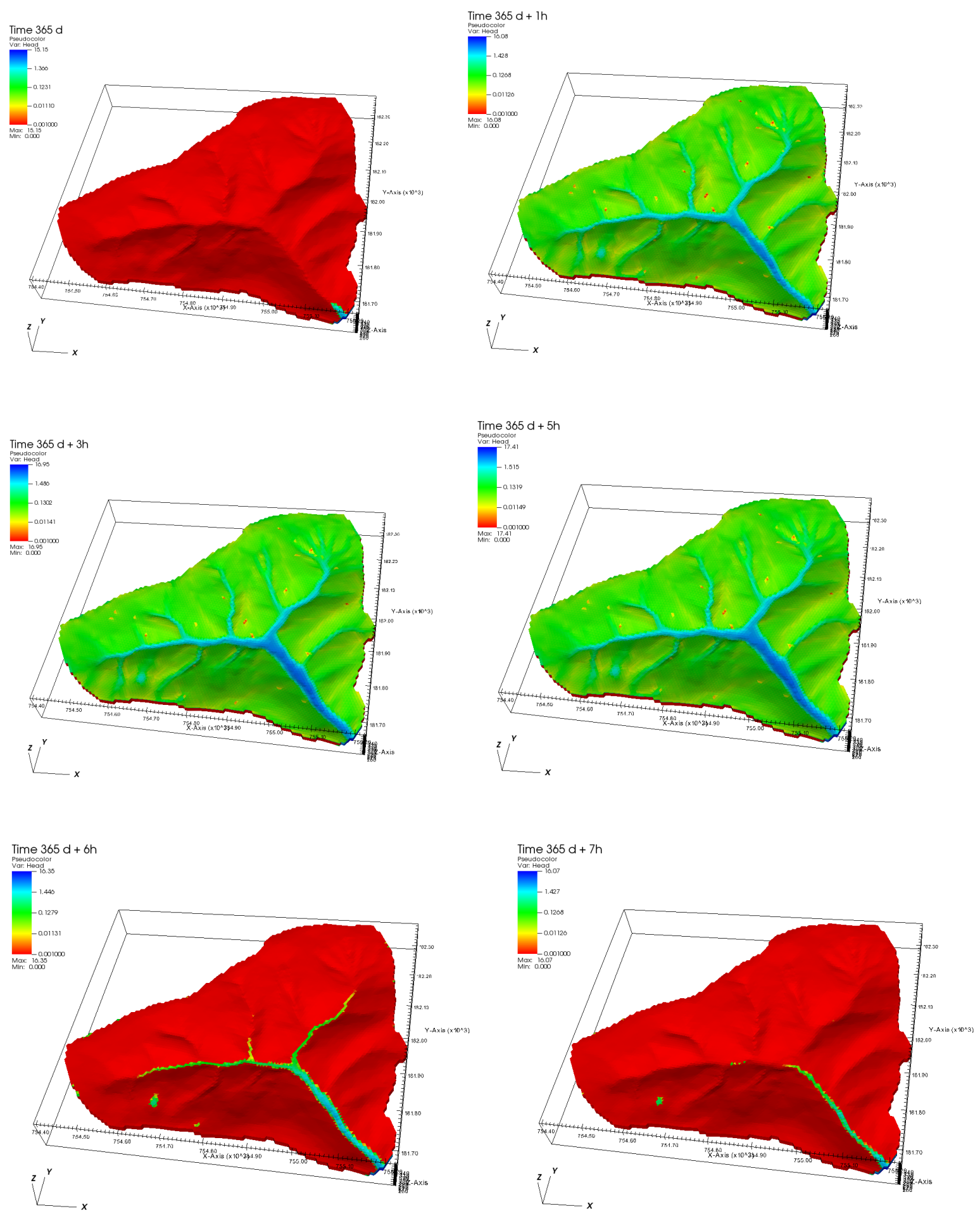

Figure 8. Results from an integrated surface/subsurface simulation of Walker Branch Watershed. Shown is surface water ponded depth before during and after a hypothetical storm event. 


\subsection{EAST FORK POPLAR CREEK WATERSHED}

The third demonstration simulation used topography of the East Fork Poplar Creek (EFPC) watershed near Oak Ridge, Tennessee. Mesh construction was similar to the Walker Branch Watershed simulations. As with that simulation, the EFPC simulation was designed to be a test of robustness, not a realistic simulation. We ran these simulations in parallel on 64 cores. Results for the surface system are shown in Figures 9-14.

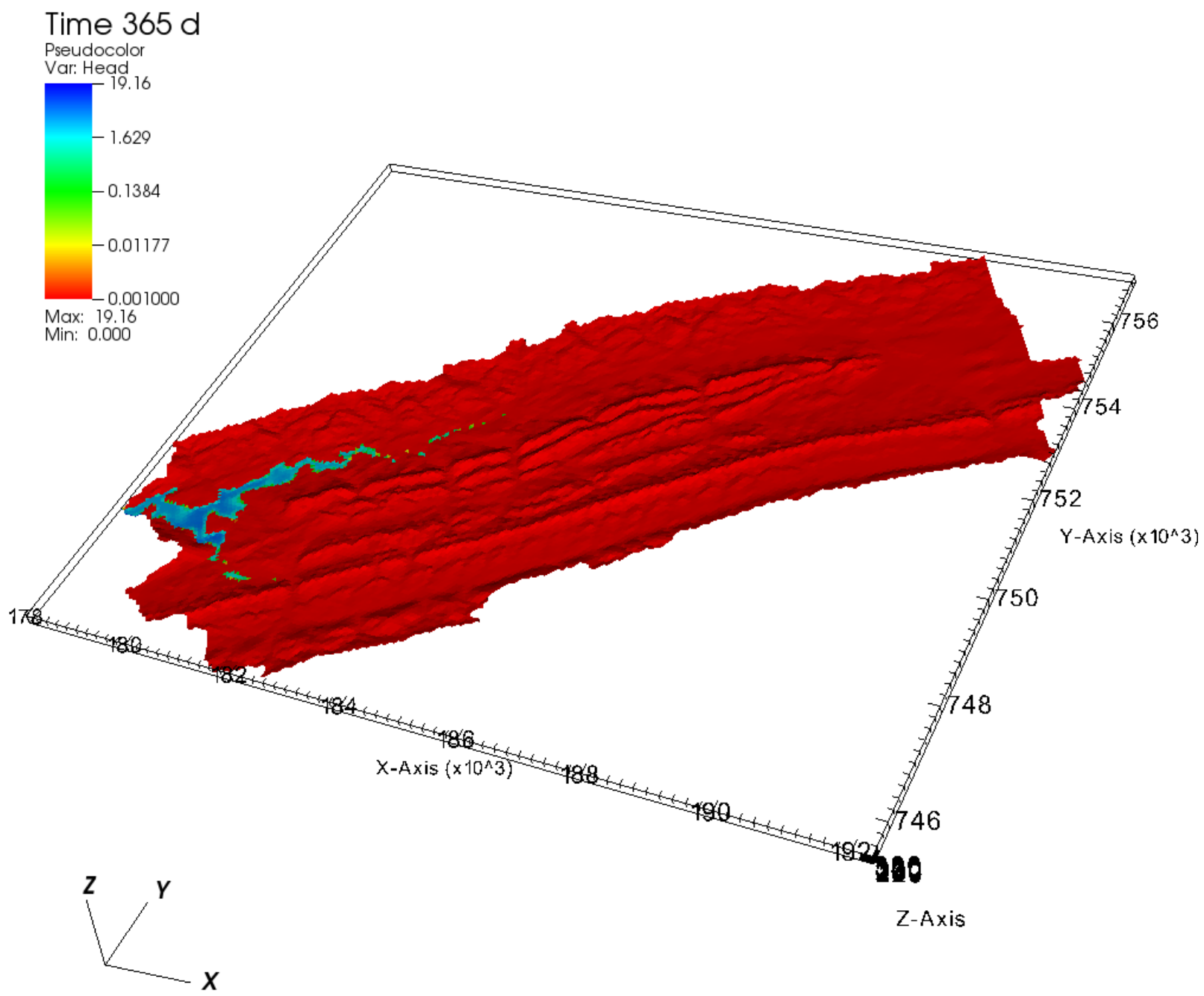

Figure 9. Results from an integrated surface/subsurface simulation of East Fork Poplar Creek Watershed. Shown is surface water ponded depth before a hypothetical storm event. 




user: ajc

Thu Dec 3 08:36:05 2015

Figure 10. Results from an integrated surface/subsurface simulation of East Fork Poplar Creek Watershed. Shown is surface water ponded depth one hour after the start of a hypothetical storm event. 


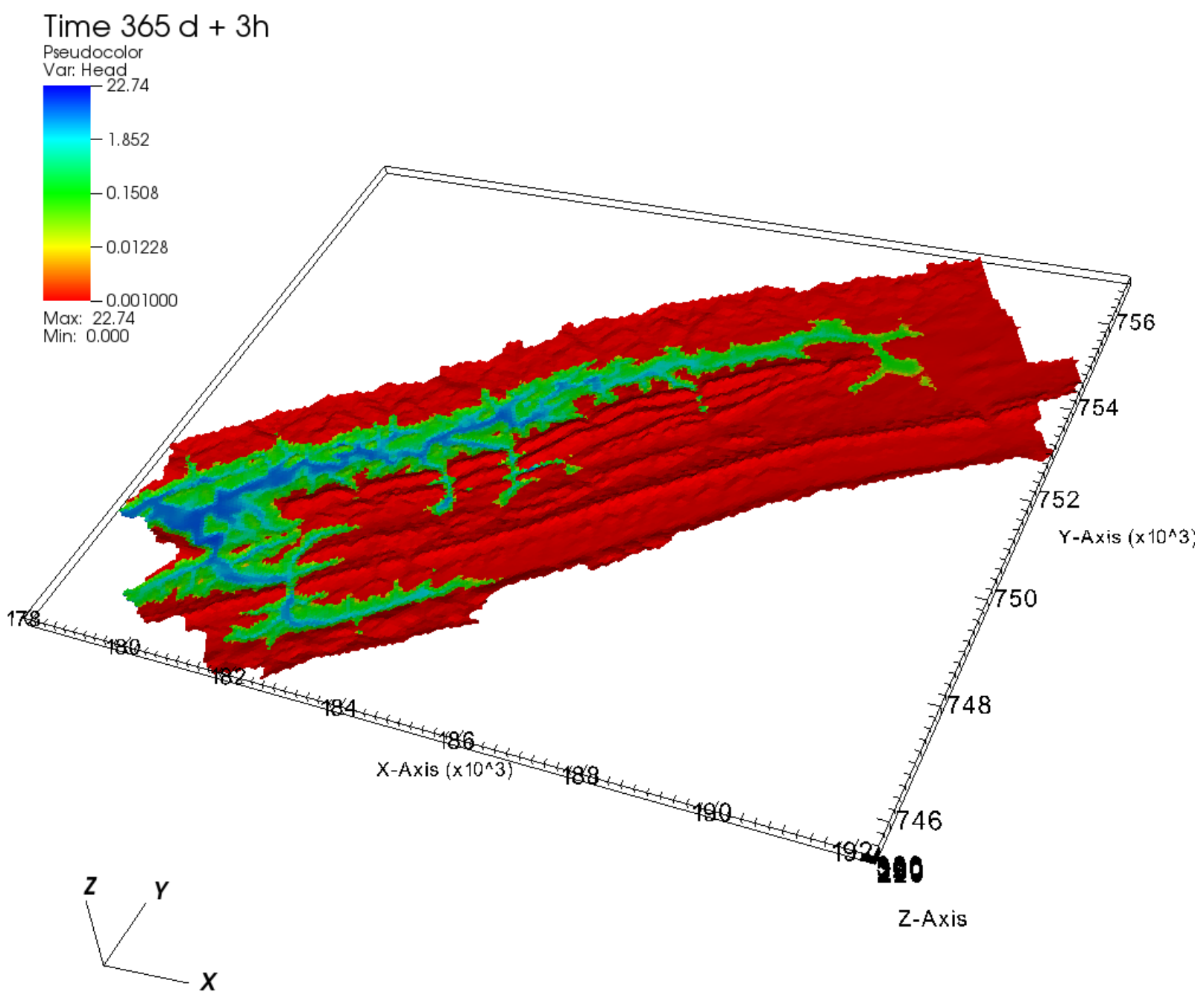

user: ajc

Thu Dec 3 08:36:55 2015

Figure 11. Results from an integrated surface/subsurface simulation of East Fork Poplar Creek Watershed. Shown is surface water ponded depth three hours after the start of a hypothetical storm event. 




user: ajc

Thu Dec 3 08:37:41 2015

Figure 12. Results from an integrated surface/subsurface simulation of East Fork Poplar Creek Watershed. Shown is surface water ponded depth five hours after the start of a hypothetical storm event. 


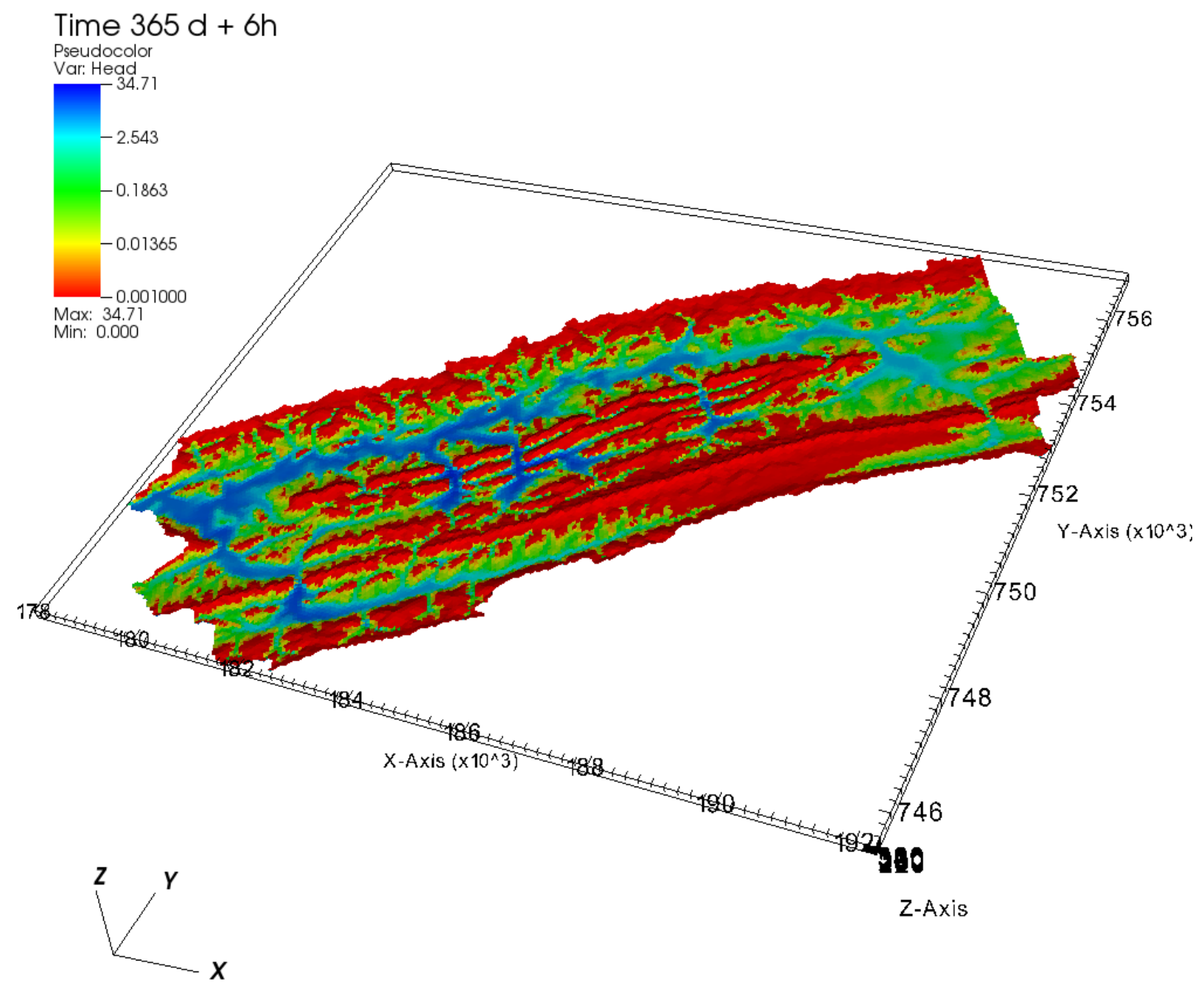

user: ajc

Thu Dec 3 08:38:21 2015

Figure 13. Results from an integrated surface/subsurface simulation of East Fork Poplar Creek Watershed. Shown is surface water ponded depth one hour after the end of a hypothetical storm event. 




user: ajc

Thu Dec 3 08:39:01 2015

Figure 14. Results from an integrated surface/subsurface simulation of East Fork Poplar Creek Watershed. Shown is surface water ponded depth two hours after the end of a hypothetical storm event. 


\section{SUMMARY AND DIRECTIONS FOR FUTURE WORK}

We developed and tested a robust scheme for adding shallow surface flow to existing subsurface flow and transport simulators. Our approach tightly couples the diffusion wave equation for surface flows with Richards equation for variably saturated subsurface flows. Our formulation is fully implicit in time and ensures continuity of pressure and flux at the land surface. In particular, we avoid the use of a conductance concept for calculating the exchange flux between the surface and subsurface domains, which has questionable physical basis.

Our approach is a tight-coupling approximation that neglects vertical gradients in hydraulic head at the land surface, allowing the surface flow and accumulation terms to be incorporated into the subsurface residual equations. This is a convenient formulation for adding surface flow terms to existing subsurface simulators because a separate surface system is not represented and a separate surface mesh is not required. Instead, the existing solution infrastructure is used, but with new terms in the residual equations and Jacobian matrix that get triggered when the liquid pressure in the uppermost cell exceeds atmospheric.

In tests using the open-source, parallel simulator PFLOTRAN, our approach was in good agreement with existing integrated surface/subsurface simulators. Tests using surface topography for the Walker Branch and East Fork Poplar Creek Watersheds near Oak Ridge, Tennessee demonstrate that the method is robust in realistic applications.

PFLOTRAN is an open-source, highly parallel subsurface flow and reactive transport simulator. Its strengths include rich and flexible geochemical reaction capabilities, good parallel scaling on mid-range and leadership-class high-performance computing resources, significant international user and developer communities, ability to use fully unstructured computational meshes, and capability to couple to the widely used land surface model CLM (Tang et al. 2016). Those capabilities make PFLOTRAN an attractive platform for next-generation process-rich watershed and ecohydrological models. The lack of a robust integrated surface/subsurface modeling capability in PFLOTRAN had previously been a barrier to that class of applications, a limitation that we removed with this work. Potential directions for future work to further improve PFLOTRAN as a platform for watershed and critical zone process modeling include better representation of root water uptake, a model for hydrological effects of forest litter, and representation of preferential (macropore) flow. 


\section{REFERENCES}

Maxwell, R.M., Putti, M., Meyerhoff, S., Delfs, J.-O., Ferguson, I.M., Ivanov, V., Kim, J., Kolditz, O., Kollet, S.J., Kumar, M., Lopez, S., Niu, J., Paniconi, C., Park, Y.-J., Phanikumar, M.S., Shen, C., Sudicky, E.A. and Sulis, M. (2014) Surface-subsurface model intercomparison: A first set of benchmark results to diagnose integrated hydrology and feedbacks. Water Resources Research 50(2), 1531-1549.

Hammond, G.E., Lichtner, P.C. and Mills, R.T. (2014) Evaluating the performance of parallel subsurface simulators: An illustrative example with PFLOTRAN. Water Resources Research 50(1), 208-228.

Lichtner, P., Hammond, G.E., Lu, C., Karra, S., Bisht, G., Andre, B., Mills, K. and Kumar, J. (2016) PFLOTRAN User Manual.

Painter, S.L., Coon, E.T., Atchley, A.L., Berndt, M., Garimella, R., Moulton, J.D., Svyatskiy, D. and Wilson, C.J. (2016) Integrated surface/subsurface permafrost thermal hydrology: Model formulation and proof-of-concept simulations. Water Resources Research 52(8), 6062-6077.

Van Genuchten, M.T. (1980) A closed-form equation for predicting the hydraulic conductivity of unsaturated soils. Soil Science Society of America Journal 44(5), 892-898.

Mualem, Y. (1976) A new model for predicting the hydraulic conductivity of unsaturated porous media. Water Resources Research 12(3), 513-522.

Painter, S., Başağaoğlu, H. and Liu, A. (2008) Robust Representation of Dry Cells in Single-Layer MODFLOW Models. Ground Water 46(6), 873-881.

Sulis, M., Meyerhoff, S.B., Paniconi, C., Maxwell, R.M., Putti, M. and Kollet, S.J. (2010) A comparison of two physics-based numerical models for simulating surface water-groundwater interactions. Advances in Water Resources 33(4), 456-467.

Kollet, S.J. and Maxwell, R.M. (2006) Integrated surface-groundwater flow modeling: A free-surface overland flow boundary condition in a parallel groundwater flow model. Advances in Water Resources 29(7), 945-958.

Wolfram Research, I. (2014) Mathematica Version 10, Wolfram Research, Inc., Champaign, Illinois.

Tang, G., Yuan, F., Bisht, G., Hammond, G.E., Lichtner, P.C., Kumar, J., Mills, R.T., Xu, X., Andre, B., Hoffman, F.M., Painter, S.L. and Thornton, P.E. (2016) Addressing numerical challenges in introducing a reactive transport code into a land surface model: a biogeochemical modeling proof-of-concept with CLM-PFLOTRAN 1.0. Geosci. Model Dev. 9(3), 927-946. 


\section{APPENDIX A. JACOBIAN TERMS WITH IN-LINE SURFACE FLOW}

The surface and subsurface components of the residual are additive $\operatorname{RES}_{i}=\mathrm{RES}_{\text {surf }, i}+\mathrm{RES}_{\text {subsurf }, i}$. We focus on the surface components

$$
\operatorname{RES}_{\text {surf }, i}=\left[\frac{\left(\eta_{l} h\right)_{i}^{t+\Delta t}-\left(\eta_{l} h\right)_{i}^{t}}{\Delta t}\right] A_{i, t o p}+\sum_{j=1}^{N_{\text {vfaces }}}\left(\eta_{l} h U_{s}\right)_{i j}^{t+\Delta t} L_{i j}
$$

Note the net infiltration term is already included in the subsurface part of the residual and jacobian in pflotran; thus we ignore it here and focus on the accumulation and flux components of the surface system.

Diagonal terms in the surface part of the jacobian are

$$
\begin{gathered}
\frac{\partial \mathrm{RES}_{\text {surf }, i}}{\partial p_{i}^{t+\Delta t}}=\frac{1}{\rho_{\text {mass }} g} \frac{\partial \operatorname{RES}_{\text {surf }, i}}{\partial h_{i}^{t+\Delta t}} \\
\frac{\partial R E S_{\text {surf }, i}}{\partial h_{i}^{t+\Delta t}}=\frac{\eta_{l} A_{i, t o p}}{\Delta t}+\sum_{j=1}^{N_{\text {vfaces }}} \frac{\partial\left(\eta_{l} h U_{s}\right)_{i j}^{t+\Delta t}}{\partial h_{i}^{t+\Delta t}} L_{i j}
\end{gathered}
$$

and off diagonal terms are

$$
\begin{gathered}
\frac{\partial \mathrm{RES}_{\text {surf }, i}}{\partial p_{j}^{t+\Delta t}}=\frac{1}{\rho_{\text {mass }} g} \frac{\partial \mathrm{RES}_{\text {surf }, i}}{\partial h_{j}^{t+\Delta t}} \\
\frac{\partial R E S_{\text {surf }, i}}{\partial h_{j}^{t+\Delta t}}=\sum_{j=1}^{N_{\text {vaces }}} \frac{\partial\left(\eta_{l} h U_{s}\right)_{i j}^{t+\Delta t}}{\partial h_{j}^{t+\Delta t}} L_{i j}
\end{gathered}
$$

Finally we need to evaluate the derivatives of the interface terms with respect to the primary variables. Because of the upwinding term, the result is different depending on the relative values of $(Z+h)_{i}$ and $(Z+h)_{j}$.

If $(Z+h)_{i}>(Z+h)_{j}$ then

$$
\frac{\partial\left(\eta_{l} h U_{s}\right)_{i j}}{\partial h_{i}}=\frac{\eta_{l} h_{i}^{2 / 3}}{n_{m a n, i j} d_{i j} \sqrt{S}}\left[\frac{5}{3}\left((Z+h)_{i}-(Z+h)_{j}\right)+h_{i}\right]
$$




$$
\frac{\partial\left(\eta_{l} h U_{s}\right)_{i j}}{\partial h_{j}}=-\frac{\eta_{l} h_{i}^{5 / 3}}{n_{m a n, i j} d_{i j} \sqrt{S}}
$$

Conversely, if $(Z+h)_{j}>(Z+h)_{i}$ then

$$
\begin{gathered}
\frac{\partial\left(\eta_{l} h U_{s}\right)_{i j}}{\partial h_{i}}=\frac{\eta_{l} h_{j}^{5 / 3}}{n_{\text {man }, i j} d_{i j} \sqrt{S}} \\
\frac{\partial\left(\eta_{l} h U_{s}\right)_{i j}}{\partial h_{j}}=-\frac{\eta_{l} h_{j}^{2 / 3}}{n_{\text {man }, i j} d_{i j} \sqrt{S}}\left[\frac{5}{3}\left((Z+h)_{j}-(Z+h)_{i}\right)+h_{j}\right]
\end{gathered}
$$

